\title{
Analysis of Transformer Resonant Overvoltages Due to Switching Capacitance
}

\author{
[ Koray Gürkan , Cengiz Polat Uzunoğlu, Serap Cekli , Mukden Uğur ]
}

\begin{abstract}
Power transformer transients, which are originated from non-linear operating characteristics, may cause failure of a power system. In this study, a special resonance phenomenon where overvoltages observed due to switching capacitances of the line is investigated. This situation is detected while high voltage side of the transformer is open circuit (no-load) and the low voltage side is connected to a transmission line through nonlinear switch (or breaker). This special resonance is caused by the interaction of leakage inductance of the transformer windings and the switching capacitance. A test setup containing $220 \mathrm{~V} / 34.5 \mathrm{kV}$ transformer is employed for realization of simulation results obtained by SPICE analysis. In order to simulate switching capacitance, a capacitance of $5.54 \mu \mathrm{F}$ is connected to low voltage side. The recorded and simulated test results show good correspondence. Observed overvoltages are analysed by continuous wavelet transform (CWT) and fast Fourier transform (FFT) techniques. Also the energy distribution, which is generated by overvoltages, is investigated by instantaneous energy levels.
\end{abstract}

Keywords-switching capacity, power transformer, overvoltage, continuous wavelet transform, resonance

\section{Introduction}

Resonance is a general term used for interactions between inductors and capacitors, which are employed to maintain the proper operation of power systems. Resonance phenomenon may cause unusual and disturbing overvoltages or currents [1].

Power transformers are the key components in power system connections and special measures should be taken into consideration to sustain overvoltage protection. Power transformer failures are not acceptable since the proper operation of a power system cannot be compromised [2]. Power transformer naturally contains leakage inductances originated from windings which are likely to cause resonance considering the capacitive effects of the line.

Koray Gürkan

University of Istanbul, Electrical and Electronics Engineering Department Turkey

Cengiz Polat Uzunoğlu

University of Istanbul, Electrical and Electronics Engineering Department Turkey

Serap Cekli

Maltepe University, Computer Engineering Department

Turkey

Mukden Uğur

University of Istanbul, Electrical and Electronics Engineering Department Turkey
During the operation of a power system the nonlinear inductance variations due to transformer core may lead to special kind of resonance which is known as ferroresonance [3]. There are some ongoing studies conducted on ferroresonance phenomenon [4-10].

In this study a $220 \mathrm{~V} / 34.5 \mathrm{kV}$ test transformer is employed to realize a special resonance condition due to switching capacitance of the line and the leakage inductance of the transformer windings. Transformer approximate equivalent circuit and transformer model are constructed. The leakage inductance and the leakage resistance of the transformer are calculated as $3 \mathrm{mH}$ and $1 \mathrm{k} \Omega$ respectively.

The possible resonance capacity is obtained as $4 \mu \mathrm{F}$ by investigating nonlinear core model of test transformer and hysteresis curve. The resonance simulations are conducted properly by using SPICE and overvoltage waveforms observed. The real case scenario is fulfilled by using $5.54 \mu \mathrm{F}$ capacity as switching capacity which is slightly different from simulation. Due to approximations and tolerances of the simulation model real resonance is obtained by using reasonable switching capacitance.

During the tests overvoltage waveforms are recorded and analysed by using fast Fourier transform (FFT) [11-12] and continuous wavelet transform (CWT) [13-15]. The switching transients are displayed efficiently by CWT analysis and an early detection method of resonance initiation of power transformers proposed.

\section{Test Set-Up}

In this study a $220 \mathrm{~V} / 34.5 \mathrm{kV}$ test transformer is taken into consideration for resonance model. In order to obtain accurate simulation, corresponding transformer tests are carried out and SPICE parameters are obtained.

\section{A. Estimation of Transformer SPICE Parameters}

In this study resonance tests are simulated by SPICE model of the test transformer. To ensure the core-loss of transformer, an open circuit test procedure was conducted. After measurements core-loss is modelled with a $1 \mathrm{k} \Omega$ resistor. Initially to measure leakage inductance, secondary of the transformer is short circuited (Fig. 1). A capacitor of $470 \mathrm{nF}$ is charged with an half-wave rectifier which rectifies main voltage. With using a SPDT switch, fully charged capacitor is suddenly connected to primary of transformer and transient oscillation at this point is recorded. 
Proc. of the Second Intl. Conf. on Advances in Information Processing and Communication Technology - IPCT 2015 Copyright $(\odot$ Institute of Research Engineers and Doctors, USA .All rights reserved.

ISBN: 978-1-63248-044-6 doi: 10.15224/ 978-1-63248-044-6-73

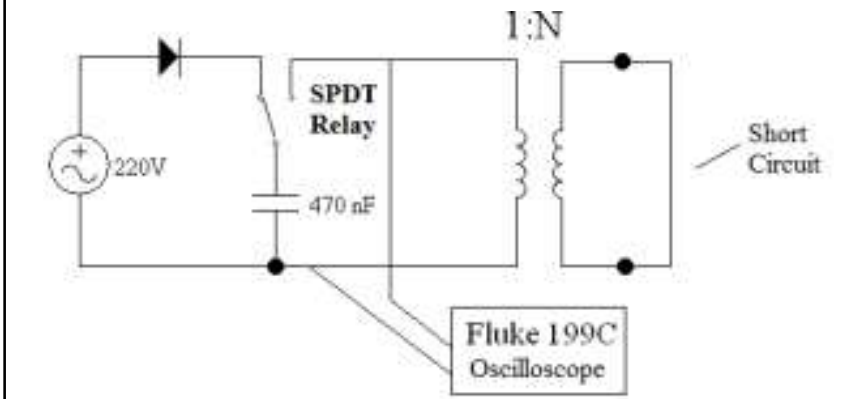

Figure 1. Experimental setup for leakage measurement

By calculating oscillation period, the leakage inductance is found as $3 \mathrm{mH}$. To predict non-linear B-H curve of transformer, input current and integral of voltage is displayed at dual trace oscilloscope with various input voltages (Fig. 2a). Here, $\mathrm{Y}$ channel corresponds integral of voltage and thus, flux linkage with $10 \mathrm{x}$ attenuation, and $\mathrm{X}$ channel corresponds to 1.6 times of current.

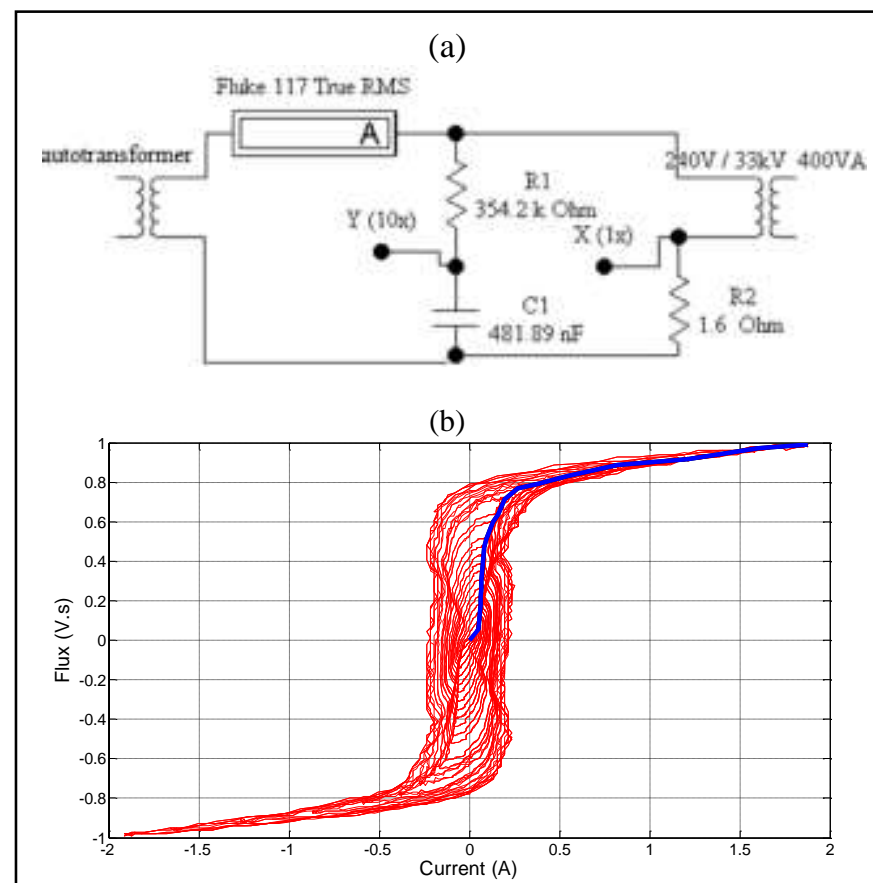

Figure 2. Experimental setup (a) and predicted B-H curve of transformer (b)

By using measured data, non-linear SPICE model of transformer is predicted by dividing B-H (Fig. 2b) curve into 15 coordinates which are obtained by different voltages supplied by autotransformer.

\section{B. Simulation Model}

The simulation model of the proposed switching scenario is given in Fig. 3. Leakage inductance of the transformer windings and transformer losses are represented by an inductance of $3 \mathrm{mH}$ and $1 \mathrm{k} \Omega$ resistor, respectively.

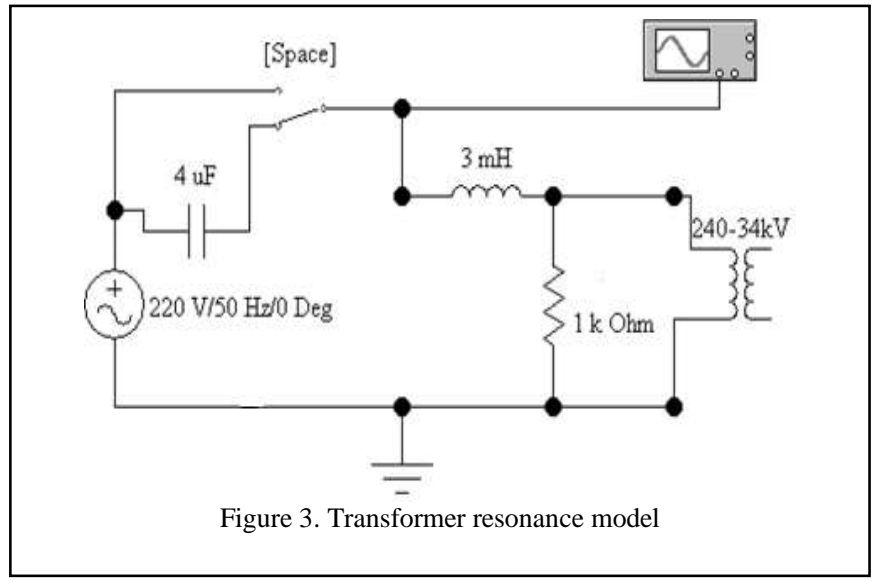

In simulation, initially, transformer is directly operated under system voltage. By pressing the space bar on the physical keyboard, SPDT switch changes its state and transformer is now in series with capacitor. Switching characteristics of the Low Voltage (LV) line is simulated by 4 $\mu \mathrm{F}$ capacitor. A dry type $220 \mathrm{~V} / 34.5 \mathrm{kV}, 400 \mathrm{VA}, 50 \mathrm{~Hz}$ test transformer, which is shown in Fig. 4 is employed to conduct real resonance tests.

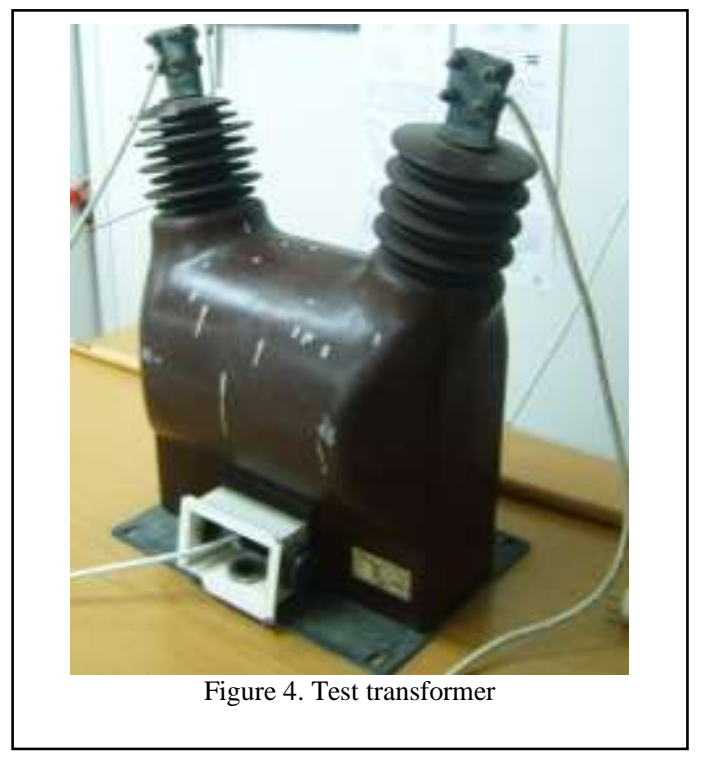

An autotransformer is used for connecting primary side of the test transformer with power network. All signal waveforms are displayed and recorded by Fluke 199C scope meter. During the tests $470 \mathrm{nF}$ and $820 \mathrm{nF}$ capacitance combinations are used for obtaining $5.54 \mu \mathrm{F}$ capacity to realize resonance. All capacitors are designed to operate under $400 \mathrm{~V}$ which is nominal voltage with tolerance for LV side. The test set-up is given in Fig. 5. 
Proc. of the Second Intl. Conf. on Advances in Information Processing and Communication Technology - IPCT 2015 Copyright $\odot$ Institute of Research Engineers and Doctors, USA .All rights reserved.

ISBN: 978-1-63248-044-6 doi: 10.15224/ 978-1-63248-044-6-73

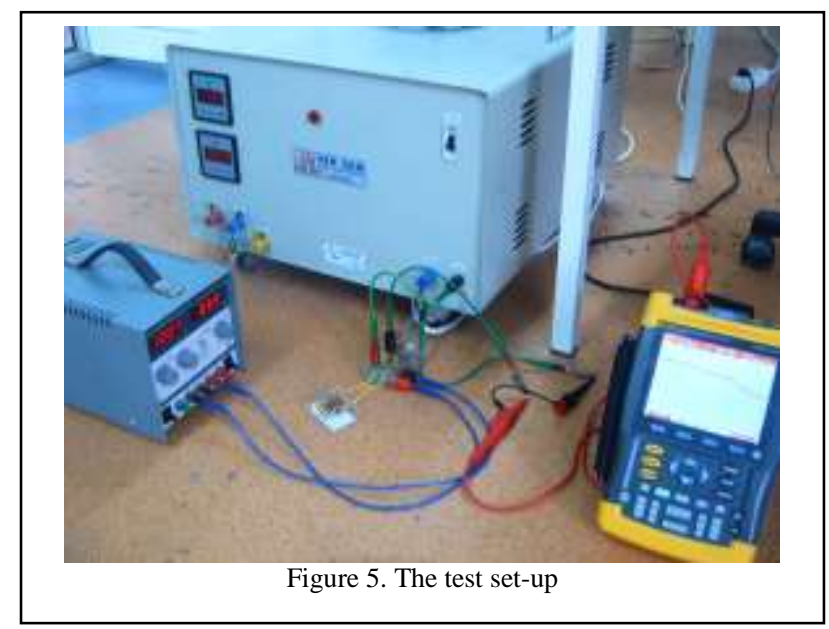

III. Simulation Results

All simulations are conducted by using Electronic Workbench program. The resonance voltage waveform is obtained according to simulation model (Fig. 3) and given in Fig. 6. The switching initiation and transition to resonance mode can be easily tracked from figure.

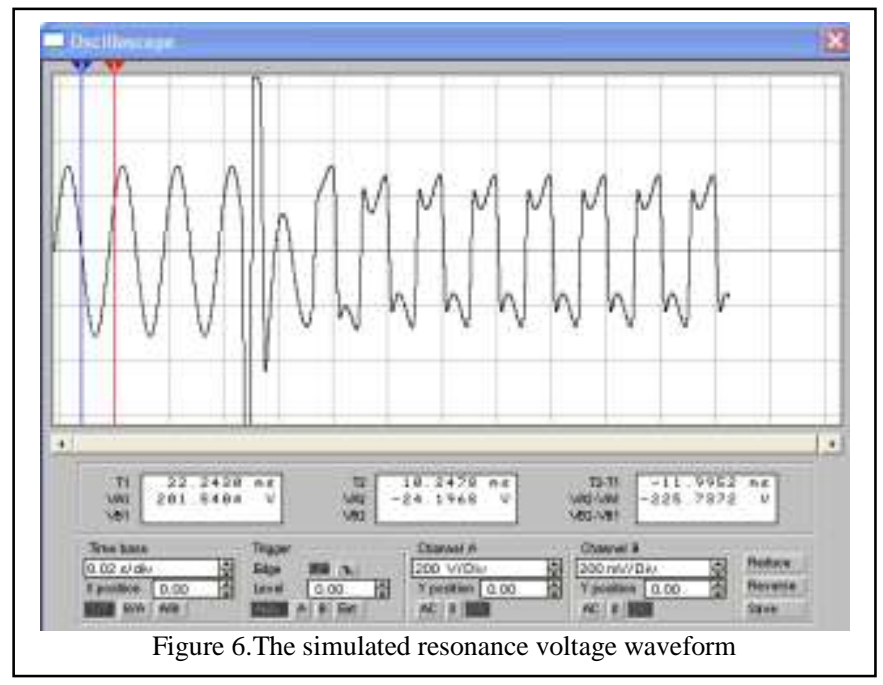

After initiation of resonance harmonics are observed on resonance voltage waveform. For this purpose FFT of voltage signal is analysed and frequency spectrum is given in Fig. 7.

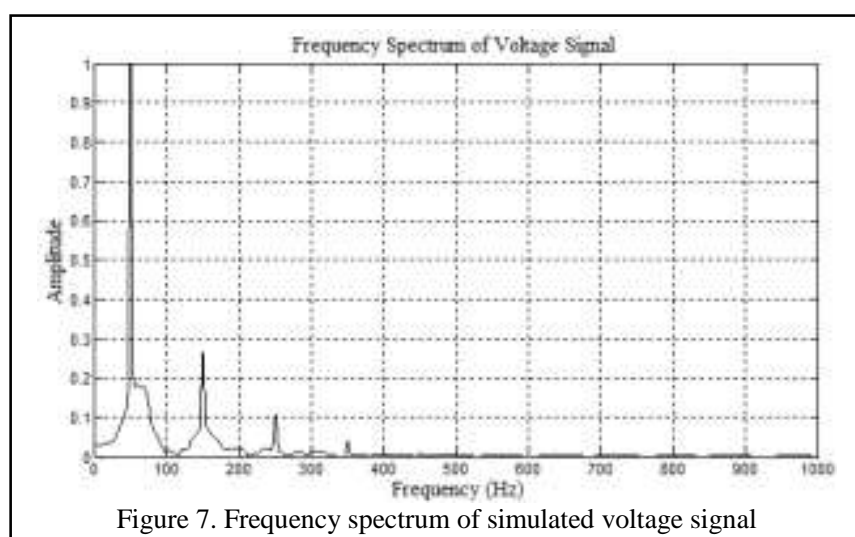

Figure 7. Frequency spectrum of simulated voltage signal
As seen from spectrum 3rd, 5th and 7th harmonics are dominant but higher harmonics are also observed.

\section{Experimental Results}

The recorded real resonance voltage waveform of test transformer is given in Fig. 8. The real resonance signal depicts similar characteristics to the one obtained from simulation results. Switching transition and harmonics are observed on the signals. Also overvoltages up to 1.5 p.u. are detected during test period which are degradative for power system components.

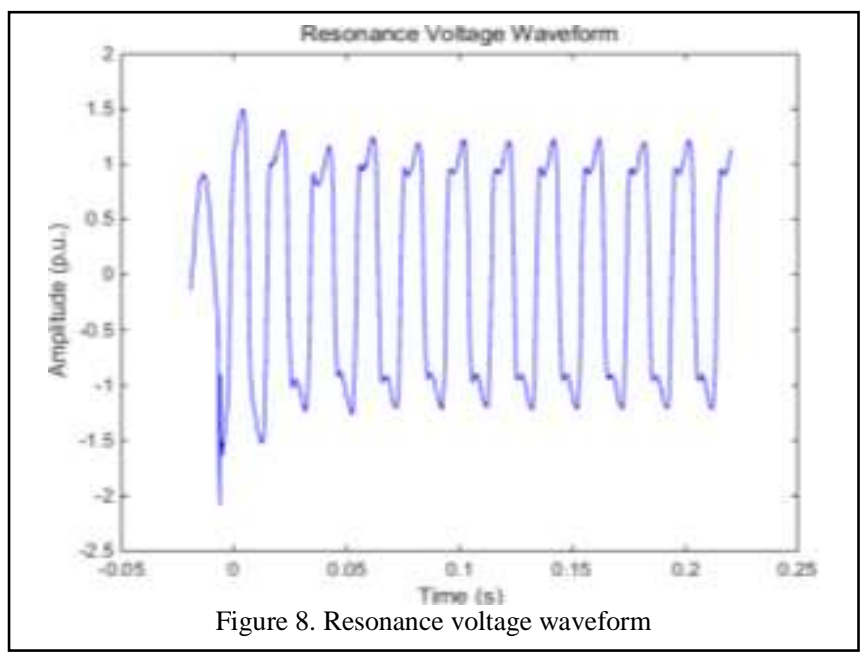

In order to reach proper comparison, frequency spectrum of the resonance voltage is given in Fig. 9. Frequency spectrum of test results depicts similar results obtained from simulation results. In accordance with previous results 3rd, 5th and 7 th harmonics are observed.

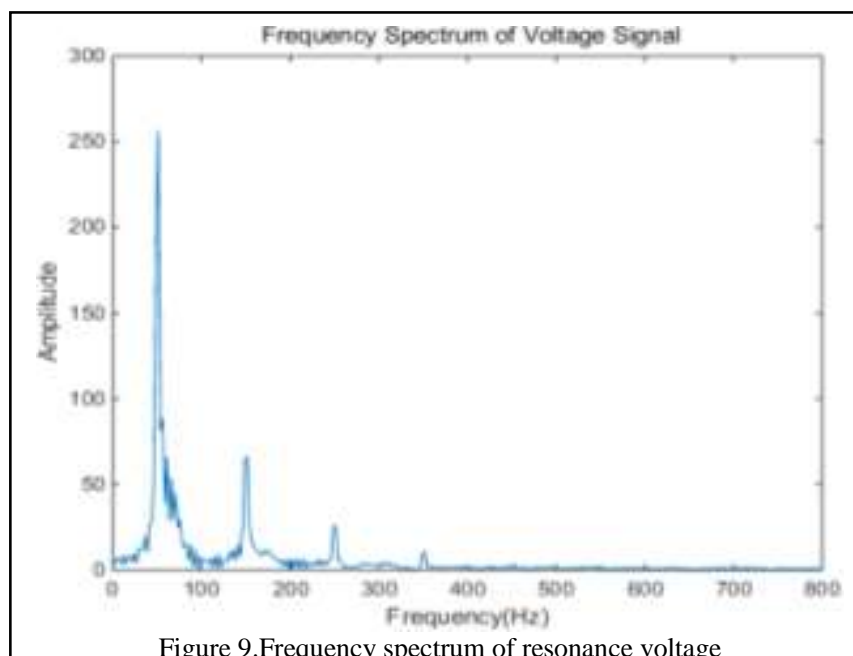

Figure 9.Frequency spectrum of resonance voltage

Beyond the FFT analysis, CWT analysis can concentrate on a limited time transition, which is displayed during the switching transients [13-14]. Peaks and oscillations are observed for limited time duration (few milliseconds). In order 
to focus on quick transitions during switching, CWT of resonance voltage is given in Fig. 10.

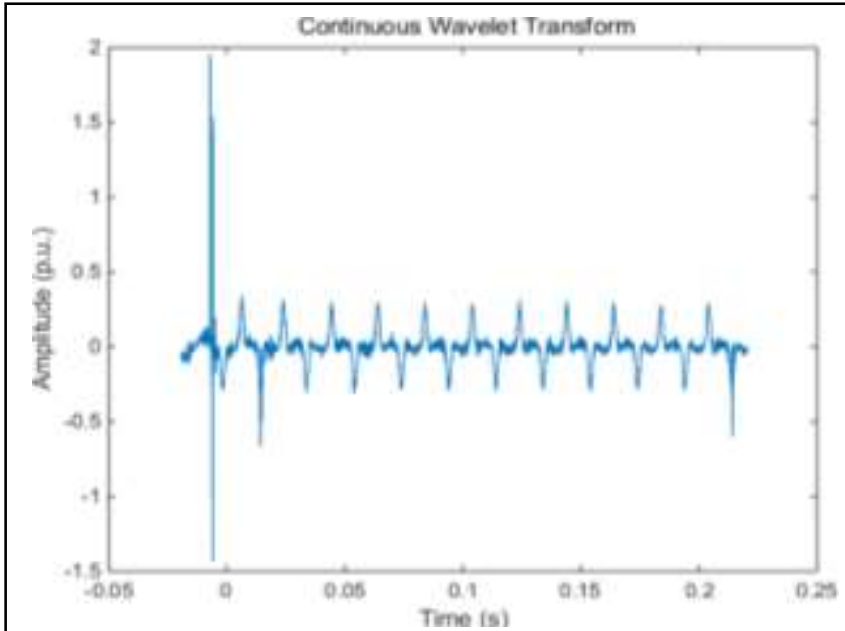

Figure 10. Continuous wavelet transform of resonance voltage

Some harmonic related transitions are displayed but most important of all the exact switching transition time can be detected with the corresponding amplitude value (2 p.u.). CWT signal transitions can reveal distinctive peak (resonance initiation) and point out system failure.

Since the instantaneous energy of non-stationary signals may represent distinctive characteristics, which has high oscillations and peaks, in this study resonance voltage signals are also analysed by energy levels. The instantaneous energy signal of resonance voltage is given in Fig. 11.

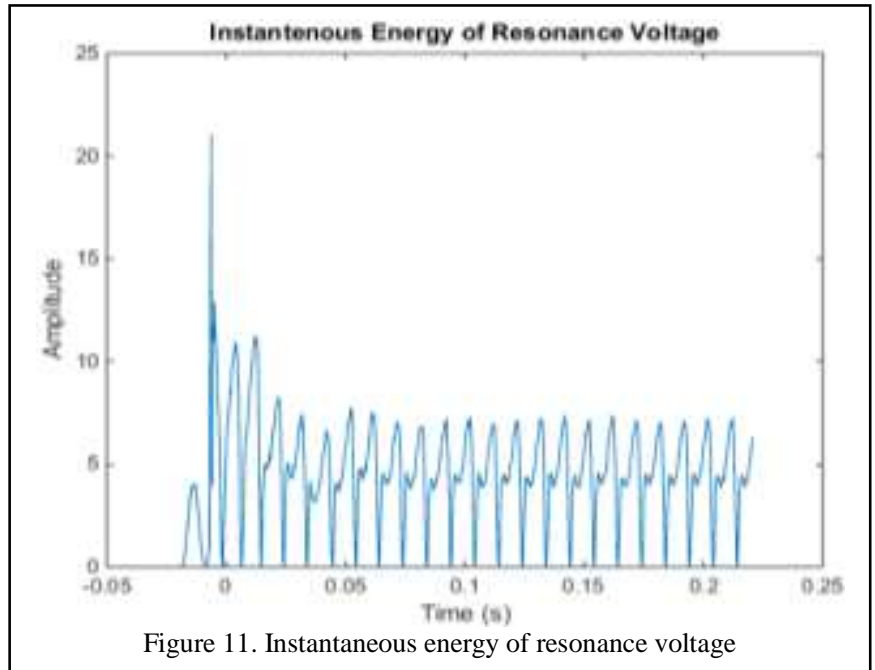

During the switching of power line instantaneous energy of voltage signal is increased approximately four times of the regular operation. After initiation signal has still two times of the regular operating state.

\section{v. Conclusions}

For the safe operation of a power system all components and corresponding signals should be observed constantly for failure. In this study a special resonance phenomenon occurred by unloaded transformer interaction with switching capacitance is investigated. During the resonance the unwanted transients such as overvoltages (up to 2 p.u.) and harmonics may cause failure of power system. Simulation results are supported with a real case scenario consisting test transformer. During the tests real capacitors are used to simulate switching capacitances. Test results depict very similar characteristic to the simulation results. FFT analysis showed that the resonance signal has higher harmonics which are capable of disruption of proper operation. Due to nonstationary signal characteristics of resonance voltages, CWT analysis is proposed for efficient detection of resonance. Also instantaneous energy level calculation method is proposed for investigation of resonance signals. During the initiation of resonance energy levels are increased significantly. Online detection of system voltage with proposed method may prevent system failure caused by unwanted resonance effect.

\section{References}

[1] B. Gustavsen, "Study of Transformer Resonant Overvoltages Caused by Cable-Transformer High-Frequency Interaction," Power Delivery, IEEE Transactions on, vol.25, no.2, pp.770-779, April 2010.

[2] G. C. Paap, A. A. Alkema, L. Van der Sluis, "Overvoltages in power transformers caused by no-load switching," Power Delivery, IEEE Transactions on, vol.10, no.1, pp.301-307, Jan 1995.

[3] E. S. Jin, X. F. Chen, G. W. Xia, Z. Q. Bo, A. Klimek, "Theoretical Analysis on Subharmonic Resonance Overvoltage," Electrical and Control Engineering (ICECE), 2010 International Conference on, pp.4470-4473, 25-27 June 2010.

[4] V. Valverde, et al. "Ferroresonance in voltage transformers: Analysis and simulations." Int. Conf. Renewable Energies and Power Quality (ICREPQ'07), Sevilla. 2007.

[5] B. A. Mork, and D. L. Stuehm. "Application of nonlinear dynamics and chaos to ferroresonance in distribution systems." Power Delivery, IEEE Transactions on vol. 9, no. 2, pp.1009-1017, 1994.

[6] P. S. Moses, M. A. S. Masoum, "Modeling ferroresonance in singlephase transformer cores with hysteresis", In Proceedings of the 8th WSEAS international conference on System science and simulation in engineering,(pp. 246-250, 2009.

[7] M. Roy, C. K. Roy, "Experiments on Ferroresonance at Various Line Conditions and Its Damping," Power System Technology and IEEE Power India Conference, pp.1-8, 12-15 Oct. 2008.

[8] D. Shein, S. Zissu, "Domains of ferroresonance occurrence in voltage transformers with or without damping reactors", Electrical and Electronics Engineers in Israel, Eighteenth Convention of, pp.1.5.2/1,1.5.2/5, 7-8 March 1995.

[9] S. Hassan, M. Vaziri, S. Vadhva, "Review of ferroresonance in power distribution grids," Information Reuse and Integration (IRI), 2011 IEEE International Conference on , pp.444-448, 3-5 Aug. 2011.

[10] C.P., Uzunoğlu, M. Uğur, "Adaptive Detection of Chaotic Oscillations in Ferroresonance Using Modified Extended Kalman Filter", Turkish Journal of Electrical Engineering and Computer Sciences, vol.21, pp. 1871-1879, 2013.

[11] R. Yang; X. Zeng; X. Yang, "Detection of ferromagnetic resonance for distribution system," Power System Technology (POWERCON), International Conference on , pp.922-926, 20-22 Oct. 2014.

[12] Y. Liu; B. Jiang, C. Wang, S. Geng, "Power system harmonic analysis based on windowed FFT and wavelet transform," Electric Utility Deregulation and Restructuring and Power Technologies (DRPT), 4th International Conference on , pp.225-228, 6-9 July 2011. 
Proc. of the Second Intl. Conf. on Advances in Information Processing and Communication Technology - IPCT 2015

Copyright $(\odot$ Institute of Research Engineers and Doctors, USA .All rights reserved.

ISBN: 978-1-63248-044-6 doi: 10.15224/ 978-1-63248-044-6-73

[13] A. Graps, "An introduction to wavelets," Computational Science \& Engineering, IEEE, vol.2, no.2, pp.50-61, 1995.

[14] D. T. Lee, A. Yamamoto, "Wavelet analysis: theory and applications", Hewlett Packard Journal, vol.45, pp.44-44, 1994.

[15] J. L. Rueda, C. A. Juarez, I. Erlich, "Wavelet-Based Analysis of Power System Low-Frequency Electromechanical Oscillations", Power Systems, IEEE Transactions on , vol.26, no.3, pp.1733-1743, Aug. 2011.

About Author (s):

Koray Gürkan received the M.Sc. and Ph.D. degrees in Biomedical Engineering from Istanbul University, Istanbul, Turkey, in 2006 and 2012, respectively. Since 2005, he has been working as research assistant in the Department of Electrical and Electronics Engineering of Istanbul University. His current research interests include metrology, sensor interface, and micro-controller based circuit design. He also carried out investigations about telemetric measurements, electronic systems of electric, hydrogen and solar cars.

Cengiz Polat Uzunoglu received the M.Sc. and Ph.D. degrees in Electrical Electronics Engineering from Istanbul University, Istanbul, Turkey, in 2005 and 2011, respectively. Since 2003, he has been working as research assistant in the Department of Electrical and Electronics Engineering of Istanbul University. His main research interests include power systems, chaotic systems, high voltage engineering and non-linear systems.

Serap Çekli received her B.Sc. degree in Electronics Engineering from Istanbul University in 2000, and M.Sc. degree in Electronics and Communication Engineering from Istanbul Technical University in 2003. She worked for Istanbul University Engineering Faculty as a research assistant between 2001-2009. She has received a Ph.D. degree from Istanbul University, Electrical Electronics Engineering Department in 2009. She works as a asistant professor at T.C. Maltepe University Computer Engineering Department since 2009. Her research interests are estimation theory,optimization theory, digital systems and design, computer architecture.

Mukden UĞUR has received his BSc degree in Electrical Engineering from Yildız University, Turkey in 1991. In 1993 he graduated from the University of Manchester Institute of Science and Technology (UMIST), U.K. with an MSc degree in Electronic Engineering. Finally in 1997 he completed his $\mathrm{PhD}$ Degree in High Voltage Engineering in the University of Manchester, U.K. From 1998 to 2005 he has worked as an Assistant Professor at the Electrical and Electronics Engineering Department of Istanbul University, where he become an Associate Professor in 2005 and Professor in 2010. He has published more than 50 national and international papers in journals and conferences. His main research interests include composite materials, surface tracking, ageing process, fractal mathematics and power systems. 